\title{
Integrating Educational Design Research and Design Thinking to Enable Creative Pedagogies
}

\author{
Dr Thomas Cochrane \\ AltLAB, Auckland University of Technology, New Zealand. \\ Joshua Munn \\ Product Design, Auckland University of Technology, New Zealand.
}

This paper explores the interrelationship between educational design research, and design thinking that guides the design stage, enabling the design of authentic collaborative mobile learning environments. As an example the article outlines the design thinking principles and processes that informed the development of wireless mobile presentation systems (MOAs) designed to create a flexible infrastructure to enable the exploration of new pedagogies in different educational contexts. The project used design thinking within an educational design research methodology to provide an in house solution to creating a supporting infrastructure to enable the implementation of a new framework for creative pedagogies and curriculum redesign. The article reflects upon example implementations of using mobile social media and MOAs as a catalyst for implementing our framework for creative pedagogies, and propose collaborative curriculum design principles for integrating the use of mobile social media within new pedagogical paradigms.

Keywords: Design thinking, Educational design research, mobile learning

\section{Introduction}

Mobile learning research has progressed through three identifiable stages (Cook, 2009; Sharples, 2009): beginning with a focus upon mobile devices, followed by a focus upon learning outside the classroom, and subsequently the mobility of the learner. More recently Cook and Santos (2016) argue that the current state of the art of mobile learning has three key foci: (1) the integration with social networks facilitating new patterns of connected social, learning and work-based practices, (2) design research providing a framework for transformative mobile learning, and (3) users actively involved in learner-generated contexts.

A focus upon the mobility of the learner (Cook, 2009; Sharples, 2009) and the current state of the art (Cook \& Santos, 2016) leads educators to integrating the use of mobile devices into learners' daily workflow and using the unique affordances of mobile devices to augment learning and capture and share students' work. However, current technology limitations in the design of mobile devices correspond with small screen size, hence mobile devices are inherently personal communication and productivity devices. These issues were core to a two-year collaborative mobile learning project between six higher education institutions across New Zealand, the AKO Aotearoa funded \#NPF14LMD project (Frielick et al., 2014). Enabling mobile collaboration was a key goal of the \#NPF14LMD project, therefore we explored options for transforming student-owned mobile devices, in particular smartphones, into group collaboration tools. The sub-project design was initially scoped as a collaborative partnership between the Centre for Learning and Teaching (CfLAT) and the Product Design Department lecturers at New Zealand university. A graduate Product Design student was then co-opted onto the project as the lead designer on the advice of the Product Design lecturers. Based upon the work on Mobile Collaborative Workstations nick-named Computers On Wheels, or COWs by Mitchel et al., (2009), M-O-bile Airplay screens (MOAs) were developed to enable students to share and interact in groups directly from their mobile devices. Using wireless screen-mirroring technologies such as Airplay (Apple Inc.), Miracast (Microsoft), Allshare (Samsung Electronics), and Google Cast, students can present the screen and audio from their mobile device onto a large-screen mobile display turning their mobile device into a group presentation and collaboration tool. Thus the idea of COWs was transformed from an essentially portable institutionally managed collaborative computing system, to become a portable collaboration system for studentowned mobile computing devices. The MOA acronym provides a New Zealand context to our design that plays on the name of the large $(3.6 \mathrm{~m}, 230 \mathrm{~kg})$ flightless bird once native to New Zealand, similar to the Emu, but now extinct. 
The focus of the educational design research (EDR) encompassing this project was to produce a home-grown solution to enabling student-owned smartphones to become part of the infrastructure hub of a mobile social media framework for new pedagogies centred on student-determined learning. As the collaborative design stage of the EDR project, key stakeholders were involved in iteratively designing and testing MOA prototypes, leading to a final production model design that is now being used in a variety of different educational contexts enabling new projects throughout the University and resulting in a veritable flock of MOAs. These MOAs can be wheeled into different spaces for students to breakout into teamwork during or in-between classes, and for a variety of other purposes.

Thus the design expanded the collaboration and connectivity affordances of mobile social media from a personal workspace into a group collaboration space. This allows a refocus in the classroom context from teacher-directed pedagogy towards student-determined learning or heutagogy (Cochrane \& Withell, 2013; Hase \& Kenyon, 2007; Luckin et al., 2010). It also enables any space with access to AC power and WiFi coverage to be used as a teamwork space.

\section{New Pedagogies}

Fundamentally our focus is upon fostering innovation in teaching and learning, enabling lecturers in higher education to think differently about teaching and learning and engage with new pedagogies that are based around social constructivism (Vygotsky, 1978), connectivity (Siemens, 2004) and student-determined learning (Hase \& Kenyon, 2001; Luckin et al., 2010). This involves a process of reconceptualising the role of the teacher, the role of the learner, and the role of technology - in this case mobile social media (Cochrane, 2014). In these new pedagogies the role of the teacher is no longer the developer or deliverer of course content, but the designer of learning experiences. For example, using a rhizomatic model of learning, Cormier (2008) conceptualises the role of the teacher as the designer of an ecology of resources (EOR) and triggering events that stimulate student discussion and creativity. However, one of the critical success factors for implementing new pedagogies identified is the development of a supporting technological infrastructure (Cochrane, 2014), and this was the focus of the MOA development project - to enable small screen mobile devices to become group collaboration tools via wireless screen mirroring. With the maturing of wireless mirroring protocols and the availability of a wide range of mobile devices that now support wireless screen mirroring the opportunity arose to leverage this technology within education at an institutionally supported level. The identified need was to design a creative, cost effective and flexible infrastructure solution that could be implemented in partnership with our institutional IT department. We were also concerned to embed critical reflection and peer feedback into the process of designing new pedagogical strategies within a variety of curriculum contexts. The scholarship of teaching and learning (SOTL (Boyer, 1990; Haigh, 2010; Weaver, Robbie, Kokonis, \& Miceli, 2012)) provides an academically rigorous reflective practice framework that can be applied to technology enhanced learning, leading to the scholarship of technology enhanced learning or SOTEL (Wickens, 2006). Therefore SOTEL was utilised to critically evaluate the broader impact of an educational design research process. The following sections explore the interrelation between mobile learning, design thinking, and SOTEL, all embedded within an educational design research methodology.

\section{Educational Design Research and Design Thinking}

Educational design research (EDR) is also referred to as design-based research (DBR). EDR is concerned with the development of practical principles for curriculum redesign, and stands in contrast to the typical comparative analysis approach of much of the educational technology research literature (McKenney \& Reeves, 2012; Reeves, 2005). EDR has similarities to action research that is concerned with transformational change through a series of iterative cycles, but adds the development of transferable design principles as a goal, bringing together research and design (Educause Learning Initiative, 2012; McKenny \& Visscher-Voerman, 2013). Within the context of mobile learning research a review of the literature (Wingkvist \& Ericsson, 2011) indicates that the predominant research methodology has been case studies (24\%) followed closely by normative (comparative analysis) research (21\%). According to Wingkvist and Ericsson, (2011), less than 5\% of published mobile learning research evidences an action research methodology or meta analysis. An earlier analysis of 102 mobile learning projects published between 2002 and 2007 revealed that the majority of mobile learning projects published in the literature focused upon supporting novice learners via content delivery to mobile devices, rather than leveraging the unique affordances of mobile devices to support innovative pedagogies. "Despite the fact that mobile phones initially started as a communication device, communication and collaboration play a surprisingly small role in Mobile 
Learning projects" (Frohberg, Goth, \& Schwabe, 2009, p. 307). Similarly, Rushby (2012) calls for "research findings that offer proof of educational, economic and social outcomes and impacts" (Rushby, 2012, p. 355). There is therefore a gap in the mobile learning research literature regarding the use of an EDR or DBR methodology. Bannan, Cook and Pachler (2015) argue that design-based research provides a methodology that aligns with the inherent messiness of mobile learning, which transcends the traditional boundaries of space, time and place associated with more traditional classroom-focused educational paradigms. EDR as a research methodology provides opportunities to explore the unique contribution of mobile learning to supporting and enabling new pedagogies. This paper explores the use of design thinking to guide the design stage process within an educational design research example.

Design thinking is sometimes conflated to be synonymous with design-based research, however the two are not equivalent. Design-based research is a broader four-stage methodology that can encompass design thinking within the design or enactment stage. This conflation of design thinking has also led to the criticism of the limited impact of DBR on teaching practice due to the separation of the roles of designer, practitioner, and researcher, and a resultant misalignment with real-world learning environments (Dimitriadis \& Goodyear, 2013; Goodyear, 2011). We argue for the integration of these roles through practitioner as researcher or the formation of collaborative teams designer/practitioner/researcher within a DBR framework. Thus to guide the development of the MOAs as part of a supporting infrastructure for EDR projects a design thinking approach was adopted.

Design thinking is not about design per se, it is about thinking differently and strategically (Scott-Webber \& Corcorran, 2013), to come up with creative solutions to real world problems leading to improved outcomes. Design thinking has become popular as a framework for creative thinking within a variety contexts, and particularly within education, where "students are challenged to embrace rapid prototyping, present multiple ideas, and test each one" (Educause Learning Initiative, 2014). Leinonen and Durall (2014) argue that design thinking provides a solution for "the need to adopt human-centered design principles in research and design of computer-supported collaborative tools" (Leinonen \& Durall, 2014, p. 107). Design thinking involves three main elements: observational research, visual sense making, and rapid prototyping. A typical design thinking process is a cycle of: empathize/observe, define, ideate, prototype, test. Embedding a design thinking process within the process of academic development and the scholarship of teaching and learning, guides the design phase of educational design research. In this project the specific problem addressed involved creating an innovative infrastructure to support the use of mobile learning in a variety of different educational contexts.

\section{A Mobile Social Media Framework for Creative Pedagogies}

Mobile learning presents unique opportunities for enabling creative pedagogies informed by foundational learning theories and frameworks. Over several iterations of mobile learning research design involving over 50 mobile learning projects since 2006, we have developed a framework that informs the curriculum design approach to a project (Cochrane \& Antonczak, 2015; Cochrane \& Narayan, 2017; Cochrane, Narayan, \& Oldfield, 2015). Our mobile social media framework is essentially a mashup of concepts that were found particularly useful to support the introduction of creative pedagogies via mobile social media. These include: the concept of the PedagogyAndragogy-Heutagogy continuum (Luckin et al., 2010), and Puentedura's (2006) SAMR model (Substitution, Augmentation, Modification, Redefinition) of educational technology transformation. Both of these pedagogical frameworks resonate with Sternberg, Kaufman and Pretz (2002) view of creativity involving incrementation (or modification of a current idea) followed by reinitiation (or redefinition). Using this framework we have designed and integrated the types of activities and pedagogies that support creativity and move beyond substitution towards redefinition, and move from teacher-directed pedagogy towards student-determined heutagogy. The framework has been refined through several mobile learning project iterations in a variety of curriculum contexts, and is summarised in Table 1.

Table 1: A framework for creative pedagogies using mobile social media (modified from Luckin et al., 2010)

\begin{tabular}{|l|l|l|l|}
\hline & Pedagogy & Andragogy & Heutagogy \\
\hline Activity Types & Content delivery & Teacher as guide & Teacher co-learner \\
& Digital assessment & Digital identity & Digital presence \\
& Teacher delivered content & Student-generated content & Student-generated contexts \\
\hline
\end{tabular}




\begin{tabular}{|l|l|l|l|}
\hline & Teacher defined projects & Student negotiated teams & Student negotiated projects \\
\hline Locus of control & Teacher & Student & Student \\
\hline Cognition & Cognitive & Meta-cognitive & Epistemic \\
\hline $\begin{array}{l}\text { SAMR } \\
\text { (Puentedura, } \\
\text { 2006; 2011) }\end{array}$ & $\begin{array}{l}\text { Substitution \& Augmentation: } \\
\text { Mobile device as personal } \\
\text { digital assistant and } \\
\text { consumption tool }\end{array}$ & $\begin{array}{l}\text { Modification: } \\
\text { Mobile device as content } \\
\text { creation and curation tool }\end{array}$ & $\begin{array}{l}\text { Redefinition: } \\
\text { Mobile device as } \\
\text { collaborative tool }\end{array}$ \\
\hline $\begin{array}{l}\text { Creativity } \\
\text { (Sternberg et } \\
\text { al., 2002) }\end{array}$ & Reproduction & Incrementation & Reinitiation \\
\hline $\begin{array}{l}\text { Knowledge } \\
\text { production }\end{array}$ & Subject understanding & Process negotiation & Context shaping \\
\hline Self perception & Learning about & Learning to become & $\begin{array}{l}\text { Active participation within a } \\
\text { professional community }\end{array}$ \\
\hline
\end{tabular}

Danvers (2003) argues that developing student creativity involves providing a learning environment that supports creativity and gives students the freedom to explore new ideas.

Creativity thrives in an atmosphere that is supportive, dynamic, and receptive to new ideas and activities. The learning environment has to encourage interactions between learners in which: action and reflection are carefully counter-balanced; open-ended periods of play and 'blue-sky' thinking alternate with goal-oriented problem-solving; stimulating inputs and staff interventions are interwoven with periods in which learners develop ideas and constructs at their own pace; critical thinking and robust debate co-exist with a supportive 'space' in which risk-taking, imaginative exploration and productive failure are accepted as positive processes of learning and, the development of meanings and interpretations is inseparable from material processes and production. (Danvers, 2003, p. 52)

This type of creative learning environment is what informed the educational design research process. Bannan, Cook and Pachler (2015) explore the intersection between mobile learning and EDR, and propose a four stage integrated design research process for mobile learning design research: informed exploration, enactment, evaluation of local impact, evaluation of broader impact. Bannan, Cook and Pachler (2015) argue that the purpose of exploring the intersection between these theories and processes "is to bring the creative (e.g. the design-seeking activity of the research team) and analytic together in a systematic but flexible manner" (Bannan et al., 2015, p. 4). In a similar way we explore the intersection of mobile learning with EDR by embedding our mobile social media framework, design thinking, and the scholarship of technology enhanced learning (SOTEL) within an overarching EDR methodology (Table 2).

Table 2: The intersection between mobile learning, design thinking, and EDR

\begin{tabular}{|c|c|c|c|c|}
\hline Methodology & \multicolumn{4}{|c|}{ Educational Design Research } \\
\hline 4 stages & $\begin{array}{l}\text { EDR Stage 1: } \\
\text { Informed } \\
\text { Exploration }\end{array}$ & $\begin{array}{l}\text { EDR Stage 2: } \\
\text { Enactment }\end{array}$ & $\begin{array}{l}\text { EDR Stage } 3: \\
\text { Evaluation: Local } \\
\text { Impact }\end{array}$ & $\begin{array}{l}\text { EDR Stage 4: } \\
\text { Evaluation: Broader } \\
\text { Impact }\end{array}$ \\
\hline $\begin{array}{l}\text { Connecting theory } \\
\text { and practice }\end{array}$ & Theory & Practice & Participant Feedback & Critical Reflection \\
\hline $\begin{array}{l}\text { Intersection with } \\
\text { mobile learning }\end{array}$ & $\begin{array}{l}\text { MSM Framework } \\
\text { informing } \\
\text { curriculum redesign }\end{array}$ & $\begin{array}{l}\text { Rhizomatic } \\
\text { Learning: } \\
\text { Developing an EOR } \\
\text { Designing } \\
\text { Triggering Events }\end{array}$ & Participant Feedback & $\begin{array}{l}\text { Peer reviewed } \\
\text { feedback via SOTEL }\end{array}$ \\
\hline Design Thinking & Observe \& Define & Ideate \& Prototype & $\begin{array}{l}\text { Iterative Testing \& } \\
\text { improvement }\end{array}$ & Wider testing \\
\hline
\end{tabular}


A key element of implementing new pedagogies is the provision of a supporting infrastructure. Design thinking was used to guide the development of a flexible infrastructure for enabling student-owned mobile devices to become collaborative tools. Therefore there were two research questions informing this project:

1. How can mobile social media be used as a catalyst to enable student-determined collaboration in and beyond the classroom?

2. How can this be supported by the design of mobile screen-mirroring systems that turn a personal mobile device into a collaborative tool?

\section{Methodology}

Through multiple mobile learning project iterations several collaborative curriculum design principles for integrating the use of mobile social media within new pedagogical paradigms were identified:

- Innovation in teaching and learning can be supported by the development of communities of practice.

- Educational design research can be informed by a simple and scalable framework for creative pedagogies using mobile social media.

- Design thinking enables the development of a simple and scalable supporting technological infrastructure for mobile learning projects.

- Both technological and pedagogical support are essential for innovative curriculum redesign, including the importance of working in partnership with the institutional IT support department (Salmon \& Angood, 2013).

- Embedding a reflective practice framework (SOTEL) critically informs the evaluation and impact of the curriculum redesign process and provides a mechanism for dissemination to a broader audience.

Our first design principle provides a key step in moving beyond substitution of previous pedagogical strategies and activities with new technologies through enabling lecturers to reconceptualise the role of technology (Cochrane, 2014). Therefore communities of practice (COP) were formed partnering educational researchers with groups of departmental lecturers to explore and experience mobile social media. One of these COPs was comprised of Product Design lecturers and the researcher, and it was out of discussions around reconceptualising mobile social media from a social domain to an educational domain that the concept of a large screen wireless mobile presentation system was developed. The concept was initially brainstormed within the Product Design COP, and consequently a graduate student was invited to take on the design process as an authentic project. The second design principle bases each project within a transferable research-informed curriculum (re) design framework. The third design principle leverages a design thinking approach to iteratively refine the design and implementation of the MOAs, with each implementation involving collaborative redesign of course activities and assessments focusing upon student-directed learning enabled by the MOAs and mobile social media. The fourth and fifth design principles were realised through a collaborative partnership between educational technology stewards, curriculum lecturers, and educational researchers, creating a team approach to curriculum design.

The following sections highlight the design thinking process that guided the design phase of our overall educational design research project, specifically the cycle of: define, ideate, prototype, test, and evaluate.

\section{Define}

We wanted to enable student-owned mobile devices, such as smartphones and tablets, to become collaborative tools utilizing social media such as Twitter, blogs, YouTube, and photo sharing. To do this we needed to devise an infrastructure for mirroring the screen of mobile devices to a larger screen or MOA. This needed to be as simple a process as possible so that the technology did not become a barrier to use, and the system needed to be as portable as possible with minimal setup required.

Specifications:

- All connectivity except power must be wireless between the mobile devices and the MOA

- The total cost must be kept below $\$ 3000 \mathrm{NZ}$ per MOA unit

- $\quad$ The cost of each individual component must be under $\$ 1000 \mathrm{NZ}$

- The system must support quality video and audio reproduction

- Internet connectivity is via the students own mobile device using the institution's WiFi network 
- $\quad$ The MOA must be portable and encourage students to move it around - therefore it must feel stable and solid and yet move easily.

Our budget determined the need to build a custom moveable TV stand, as commercially available products were too expensive. The price point also dictated that the optimal TV screen would be a 50-inch plasma or LED with basic HDMI and optical audio connectivity.

\section{Ideate}

The design process involved two steps: the design of the technology required, and the design of a mobile stand to house and move the technology. Wireless connectivity was achieved simply using an AppleTV (for iOS devices) or a Samsung wireless Allshare media streaming hub (for Android devices) connected via WiFi to students' mobile devices, and connected via HDMI to a 50 inch TV screen. Audio was enhanced by connecting the optical audio output of the TV to a high quality portable sound system mounted on the MOA stand. All devices were mounted on the stand, leaving only a single power cable to be plugged in. Laminated wood was utilised as the material for the stand, mainly from an aesthetic perspective in comparison to the spartan designs of commercially available metal moveable TV stands. This meant that a single sheet of laminated plywood could be used for each stand with all parts cut from a single sheet of plywood using a CNC machine, minimising cost and wastage of material. AutoCAD was used to draft a plan for the stand in such a way that the stand could be assembled using a minimum of screws and bolts, utilizing a slot joint system (Figure 1).

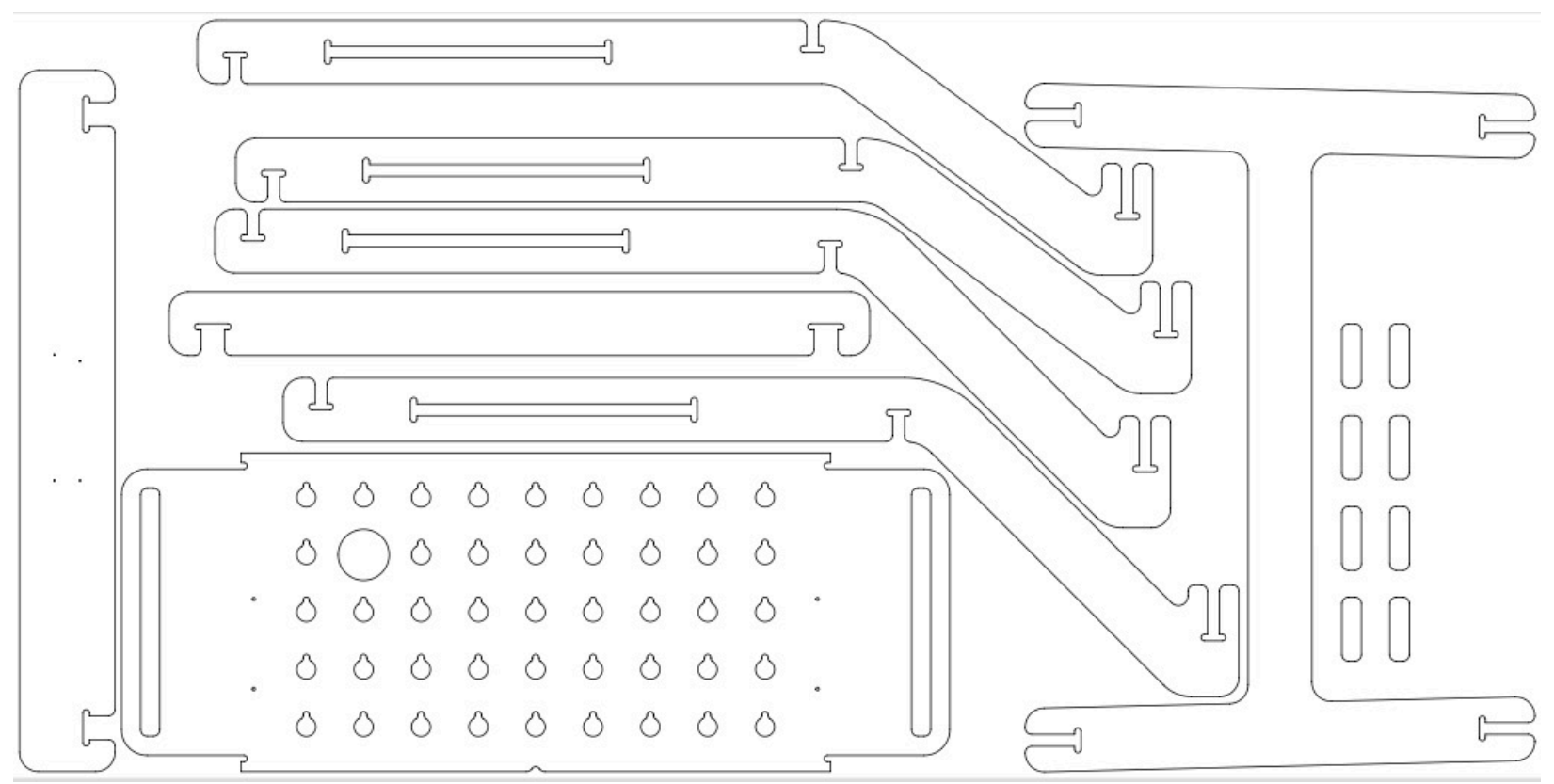

Figure 1: MOA CNC cutout design

\section{Prototype}

The MOA stand went through three design iterations before settling upon a design for production. The Product Design lecturers and the researcher as the key stakeholders gave feedback on the stand design iterations. The first prototype used conservatively too much plywood and was consequently overly heavy. The first iteration of wheels used was found to provide limited mobility, particularly over rough surfaces when the MOA was moved between buildings or not on a flat-carpeted surface. Thus the design was altered to halve the structural joints, and larger and higher quality wheels were specified. The second iteration of the MOA stand integrated the cable management between the devices mounted on the stand. While lighter and more manoeuvrable, the second iteration of the MOA stand was found to flex too much when moved. The third iteration of the MOA stand repositioned the main braces of 
the structure to provide overall stiffening and strength without adding more material. Figure 2 shows the prototype MOA alongside a production MOA.

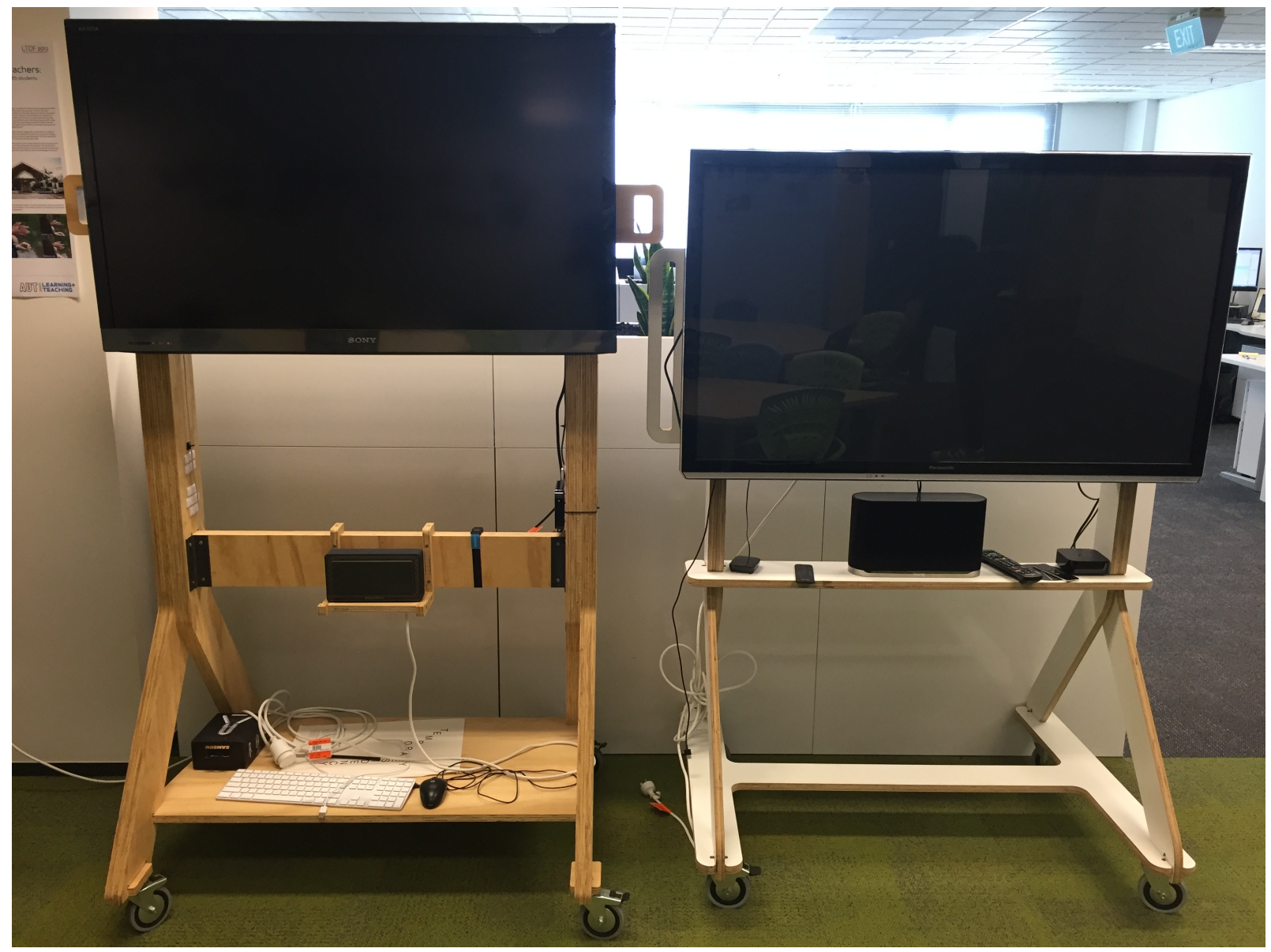

Figure 2: Prototype Moa (left) and Production MOA (right)

WiFi connectivity for the MOA required working with the institution's IT department to create a test network that enabled iTunes, Airplay, and DLNA media streaming. A separate network name (SSID) was created and activated on wireless Access Points (APs) in any area that the MOAs would be used.

\section{Test}

The build and test stages spanned iterative cycles as the project progressed through the stages of prototype, pilot implementation, and several full production iterations. The collaborative design of learning activities and assessments using mobile social media and the impact of the MOAs were tested in several different higher education contexts as briefly described in the following case studies. Each implementation case study involved the formation of a community of practice of lecturers in a department and the researcher. The researcher demoed the use of the MOA and brainstormed the integration into the curriculum of mobile social media with several groups of lecturers, who met weekly over a semester to explore the potential of new pedagogies enabled by mobile social media.

\section{Evaluate}

A MOA user survey was conducted to gain feedback upon the design and usage of the MOAs. Twelve lecturers who had been assigned MOAs as part of internally funded mobile learning projects were invited to complete a short 5 question survey designed to gather feedback on the experience of using the MOAs within their project contexts, and gather suggestions for future design improvements. Seven lecturers responded and completed the survey 
(https://www.surveymonkey.com/results/SM-J8JJFVRR/). The responses were anonymous, and the five questions included:

1. How often did you use the MOA?

2. For what purposes did you use the MOA?

3. In what situations are the MOAs most useful?

4. How could the MOAs be improved?

5. Do you have any other feedback comments?

The survey responses indicated that the usage of the MOAs within these projects varied from regular (at least weekly) use (43\%) to occasional use $(57 \%)$ of the MOAs. The MOAs were put to a variety of uses throughout the projects, with the predominant use being for wireless screen-mirroring from mobile devices $(71 \%)$ and for live backchannel streams (such as Twitter streams and Todaysmeet discussions) in classes (57\%). As indicated by the variety of uses reported in table 3 the MOAs were found to be a flexible enabling technology infrastructure component within these projects - multiple uses per respondent were allowed.

Table 3: Responses to "For what purposes did you use the MOAs?"

\begin{tabular}{|l|l|}
\hline MOA usage scenarios & Responses \\
\hline Wireless screen mirroring from mobile devices & $71.4 \%$ \\
\hline For live backchannel streams & $57.14 \%$ \\
\hline To facilitate meetings & $42.86 \%$ \\
\hline As a main class presentation system in class & $28.5 \%$ \\
\hline Break-out sessions & $28.5 \%$ \\
\hline For guest video conferences & $28.5 \%$ \\
\hline For student remote presentations & $28.5 \%$ \\
\hline For student teamwork & $14.29 \%$ \\
\hline For flexible environments where there is not a main video projector & $14.29 \%$ \\
\hline To create a walk-in culture for meetups where participants showcase their work & $14.29 \%$ \\
\hline End of semester student exhibitions & $14.29 \%$ \\
\hline Displaying promotional material at events & $14.29 \%$ \\
\hline
\end{tabular}

While answering question 3 the respondents agreed there were multiple uses for the MOAs, the highest ranking uses were to facilitate student team projects, and as a main presentation system.

Suggested improvements to the MOAs highlighted enabling cross-platform screen mirroring (which was not an initial feature of the MOAs but developed as cross-platform Apps and device capabilities converged), and provision of a more robust WiFi network. There were several suggestions regarding the physical design of the MOAs for more flexibility of wired connectivity, and ease of single-user portability.

\section{EDR Implementation Case Studies}

An EDR methodology was implemented (Table 2) to explore creative pedagogies in a range of contexts. The EDR methodology provided a structure for collaborative curriculum redesign supported by the partnership of educational researchers and discipline lecturers, forming communities of practice to explore the application of mobile learning to their own curriculum contexts. The design and introduction of the MOAs was integrated into these projects as an enabling technology, and funded through applications for contestable institutional research funds via the Learning and Teaching Development Fund (LTDF). This section explores three examples of implementing this EDR methodology in three different curriculum contexts across the university enabled by the design and use of MOAs. The three projects were linked via participation within a connectivist Massive Open Online Course (cMOOC) - the Mobile Social Media Learning Technologies cMOOC (MOSOMELT) - that was designed as a network of communities of practice for sharing ideas and practice (Cochrane \& Narayan, 2016; Cochrane, Narayan, BurcioMartin, Lees, \& Diesfeld, 2015). The application of the overall project design principles to the three curriculum contexts followed a common process as summarized in Table 4. 
Pacific Journal of Technology Enhanced Learning, 2020, 2(2).

Table 4: Applying a mobile social media framework in the curriculum projects

\begin{tabular}{|l|l|l|}
\hline \multirow{2}{*}{ Design Principles } & Design of project elements \\
\cline { 2 - 3 } & Ecology of Resources & Triggering Events \\
\hline COP formation & $\begin{array}{l}\text { Collaboration tools for project } \\
\text { planning: e.g. Google Plus } \\
\text { Community, Google Docs, Twitter }\end{array}$ & $\begin{array}{l}\text { Collaboration between lecturers and } \\
\text { academic researchers, participation in a } \\
\text { cMOOC (MOSOMELT) }\end{array}$ \\
\hline $\begin{array}{l}\text { Embed a DBR } \\
\text { methodology }\end{array}$ & $\begin{array}{l}\text { Support lecturer culture of } \\
\text { exploration, and iterative design and } \\
\text { evaluation via participation within } \\
\text { communities such as ResearchGate, } \\
\text { and Certified Member of the } \\
\text { Association for Learning tehnology } \\
\text { (CMALT) }\end{array}$ & $\begin{array}{l}\text { Design new curriculum assessment } \\
\text { activities informed by our mobile social } \\
\text { media (msm) framework }\end{array}$ \\
\hline Supporting infrastructure & $\begin{array}{l}\text { Deployment of 4 MOAs and mobile } \\
\text { devices for lecturers }\end{array}$ & $\begin{array}{l}\text { LTDF project proposal application } \\
\text { funding }\end{array}$ \\
\hline $\begin{array}{l}\text { Technological and } \\
\text { pedagogical support }\end{array}$ & $\begin{array}{l}\text { Activation of wireless mirroring } \\
\text { protocols on wifi network. } \\
\text { Design of negotiated ecology of } \\
\text { resources enabling student-generated } \\
\text { content }\end{array}$ & $\begin{array}{l}\text { Assessment activities designed as a } \\
\text { series of triggering events to stimulate } \\
\text { student collaboration and sharing of } \\
\text { their projects }\end{array}$ \\
\hline Embedding SOTEL & $\begin{array}{l}\text { Collaborative reflection and research } \\
\text { writing tools: Wordpress, Google } \\
\text { Docs, Evernote. }\end{array}$ & $\begin{array}{l}\text { Gather feedback through SOTEL } \\
\text { Publication of project outcomes at } \\
\text { international conferences, journal } \\
\text { articles, and edited book chapters }\end{array}$ \\
\hline
\end{tabular}

\section{Game Design}

This project began with the aim of supporting the development of a new Game Design degree. The goal of this new degree is to transform students into creative professionals, by focusing upon ontological pedagogies (Danvers, 2003) that deal with the process of becoming, rather than pedagogies that focus upon knowledge transfer. Thus the new degree focuses upon extending students' experience and expertise beyond the formal requirements of the degree to give them a real world collaborative experience of becoming part of the professional community of game developers modeled within a collaborative design studio experience.

The project focused upon collaborative design of new learning experiences for students in the Game Design course, for example: students could use their own mobile devices to present in class reports and participate in live critiques via the MOAs. Active student participation within a national game developer community was achieved through a monthly game developers meetup, where the MOAs have enabled interactive game development demonstrations as part of an open interactive studio space environment that models best practice. Through the use of MOAs and screen mirroring, students were encouraged to work collaboratively in the studio spaces whereby game design processes were demystified by third year students modeling their project workflows via screen-mirroring their devices to the MOAs for first and second year students to observe within the studio. Reflections on the game design project are regularly updated and archived on a Google Plus Community: http://bit.ly/1BexeAT. Critical reflection on the project via SOTEL outputs include: conference presentations and an ebook chapter (Cochrane, Narayan, et al., 2014; Kenobi \& Cochrane, 2015).

\section{Journalism}

The integration of mobile social media within the journalism curriculum was initially triggered by a discussion between the course lecturers and the researcher as an academic advisor around how to stop students disengaging in class by constantly updating their Facebook status. This led to the establishment of a community of practice of 
lecturers and the academic advisor exploring ways to authentically integrate the use of mobile social media (for example Twitter and Instagram) within the journalism curriculum. This project involved the collaborative redesign of a New Media Journalism paper from a previous focus upon teaching students rudimentary web 1.0 development skills and the PowerPoint presentation of social media case studies from the lecturers, to providing students with an authentic experience of using and critiquing mobile social media as it has transformed contemporary journalism practice. This redesigned level 7 paper offers students authentic team-based projects in which they are included as active negotiators of the project outcomes (heutagogy).

In this project students build a professional mobile social media identity throughout the course, and enage with mobile social media both during their class time and beyond class. Thus graduates are better prepared to become active members of collaborative mobile social media journalism teams, both nationally and internationally. In this context the MOAs were used to display: either Twitter streams during class or a Todaysmeet.com backchannel creating an interactive crowd-sourced mobile discussion forum, student presentations from their mobile devices (for example: http://youtu.be/a5813L5O18E), and guest lecturers via Skype and other mobile live streaming Apps. The use of the MOAs made the backchannel conversations around class discussions and topics explicit and interactive. These live discussion forums were also able to be recorded and any questions followed up after class. Reflections on the Journalism project are updated on a Wordpress blog http://ejeteam.wordpress.com, and archived on a Google Plus Community http://bit.ly/mojomlaw. SOTEL outputs from this project include conference presentations, Journal papers, and book chapters (Cochrane, Antonczak, et al., 2013; Cochrane, Mulrennan, Sissons, Pamatatau, \& Barnes, 2013; Cochrane, Sissons, Mulrennan, \& Pamatatau, 2013).

\section{Performance for Screen Studies}

In 2013 the performance for screen course was relocated into a new building space that incorporated state of the art performance facilities for drama, dance, and live theatre. However, no thought had been given to providing either audio visual or wireless infrastructure to enable presentation and collaboration technologies within this space, which was designed as a blank performance environment.

The use of three MOAs and iPad minis for the course lecturers enabled this space to be used for a range of activities: for lecturers to wirelessly present, for students to record their performances, play them back on the MOAs, critique their performance, and view and discuss supporting material in the performance space rather than in a separate classroom space. This project also resulted in the development of a guide to the use of the MOAs by one group of the project participants that was shared between all the project participants. Example lecturer initial reflections on the use of the MOAs in 2013 are transcribed below.

We've been using the MOA and the iPad minis in our teaching. Initially we were using it as a presentation device, which has limitations and it is difficult to transfer files to the iPad. For example PowerPoint on the iPad messes up fonts and layouts and embedded videos do not play. However there are other applications of the devices that are quite useful, for example showing videos using GoodReader, and being able to immediately show student videos straight after they are recorded is great. So part of the relevance for our context of performance for screen is that students can use the technology to film themselves doing things and then immediately show the rest of the class and form the basis for a discussion. We are also looking at ways of creating online communities where students can discuss things amongst themselves and present assessments less as written activities than as video blogs of their performance - we're teaching them performance, so rather than writing it down as a journal entry they can express their performance as a combination of written and video reflections. (Lecturer reflection, 2013)

A survey of students conducted in 2014 revealed that all the students enrolled in the course owned smartphones (either iPhones (90\%) or Android (10\%) smartphones), thus the second iteration of this project focused upon redesigning the course activities and assessments around the use of student BYOD devices and Wordpress.com student ePortfolios. Students also explored mobile augmented reality applications displayed in teams via the MOAs. Reflections on the performance for screen project are archived on a Google Plus Community http://bit.ly/GA4kQW and a Vimeo channel (https://vimeo.com/channels/1001895). SOTEL outputs from this project include conference 
presentations, Journal papers, and book chapters (Cochrane, Guinibert, Simeti, Brannigan, \& Kala, 2014; Cochrane, Narayan, et al., 2014).

\section{Discussion}

Over the period of two years twenty-eight MOAs were produced and utilized within a variety of mobile-learning enhanced curriculum context projects. The prototype stage produced three iterations of the MOA design, and there were four subsequent production runs of 5-6 MOAs each. Adopting a design thinking process for the development of the MOAs formed part of an overall educational design research methodology informed by our mobile social media project framework. Thus the development of a supporting infrastructure (MOAs) has been key to enabling new pedagogies within a variety of contexts as illustrated by the brief case studies included in this paper. A key goal of the MOA design was to minimise the technical requirements for mirroring a student-owned mobile device to a large screen by utilizing the built-in screen mirroring capability of iOS and Android mobile devices. Therefore the MOAs were designed to require only a simple WiFi login process with a simple password on each MOA and a single cable required for power. This allowed us to focus more upon pedagogical redesign without the technology getting in the way of pedagogical innovation. The problem observed is that education is invariably driven by IT decisions that determine teaching and learning opportunities rather than seeing IT as an enabler of new pedagogies and creativity. When the technology gets in the way of creative teachers and learners then the problem is with the technology, not the teachers or learners. Technology must be reconceptualised as creative tools that enable innovative pedagogies. Driving teaching and learning from IT decisions rather than pedagogy propagates the substitution of old pedagogies onto new technologies, leading to the phenomenon of no significant difference (Reeves, 2005). Rather than limiting creative teachers and learners, ICT should empower them, and appropriate technology choices be made to do this. In 2013 the European Commission presented their vision for creative classrooms where the theme was up scaling innovation in teaching and learning (Punie, 2013), this vision places ICT infrastructure as an enabler rather than the driver of creative classrooms: http://is.jrc.ec.europa.eu/pages/EAP/SCALECCR.html. Within our model of educational design research this process is informed by our mobile social media framework for creative pedagogies.

The development of the MOAs has enabled the integration of new pedagogical practice within several departments across the university. However, while the use of MOAs was found to be beneficial in small group tutorials, and flexible learning spaces enabling student team project work using their own mobile devices, their use within computer lab situations was less successful due to the restriction of sightlines created by the large screen computer monitors. Connecting an AppleTV to a large screen video projector was found to be more effective in computer lab environments.

The rapidly evolving nature of mobile devices and large screen development has meant that every iterative production run of the MOAs has required tweaking of the MOA design to accommodate new components as prior models become unavailable. In particular this has meant replacing the original 50 -inch plasma screens with 50 inch LED screens, and new wireless audio units in each MOA production run. In general these updates have been beneficial: for example the 50 inch LED screens are $10 \mathrm{~kg}$ lighter than the original plasma screens, making the MOAs easier to move. The iterative software updates available for the AppleTV since the initiation of the project have also provided solutions to some of the initial security and connectivity issues that were concerns for the institution's IT department. In particular, the AppleTV and iOS have been updated with Airplay across WiFi subnets and discovery of Airplay devices via Bluetooth. This means lecturers and students no longer have to switch WiFi subnets and daily login to the institutions proxy network to gain access to both the Internet and Airplay mirroring to the MOAs. Additionally there have been several Android and Windows OS applications developed to enable crossplatform screen-mirroring to AppleTV devices, for example: Airserver Connect (for Android devices), and Air Parrot for Windows devices. These advances mean that the end user experience is more seamless, encouraging the use of the technology.

Following a design thinking process has led to several practical solutions to the availability and supply of the MOAs. The design of the MOAs stands as a CNC file cut from a single sheet of plywood and press fit assembly has enabled sharing the design with other New Zealand institutions either as a pre-cut flat-pack for on-site assembly, or via sharing the CNC files to institutions with their own CNC facilities to cut and assemble their own MOAs on site. 
Embedding the use of MOAs as curriculum redesign enablers within a reflective practice framework (SOTEL) also enabled the documenting and sharing of pedagogical redesign experiences with other institutions globally - both through conference presentations and publications, and journal articles based upon our experiences.

This case study illustrates the intersection of educational design research and the unique affordances of mobile learning, and has resulted in the identification and refinement of several collaborative curriculum design principles for integrating the use of mobile social media within new pedagogical paradigms:

- Educational design research can be supported and informed by a simple and scalable framework for creative pedagogies using mobile social media.

- Design thinking enables the development of a simple and scalable supporting technological infrastructure for mobile learning projects.

- Both technological and pedagogical support are essential for innovative curriculum redesign, including the importance of working in partnership with the institutional IT support department (Salmon \& Angood, 2013).

- Embedding a reflective practice framework (SOTEL) critically informs the evaluation and impact of the curriculum redesign process and provides a mechanism for dissemination to a broader audience.

These design principles can be applied to a variety of curriculum design contexts involving mobile learning as an enabler of creative pedagogies.

\section{Conclusion}

Embedded within an educational design research methodology, this project used a design thinking approach to find a creative solution to our goal of enabling student-generated contexts and collaboration via mobile social media. This involved the development of a portable wireless infrastructure for enabling screen mirroring from student owned mobile devices. This low cost technological solution (MOAs) has been successfully shared and implemented with other New Zealand institutions. Partnering with various lecturers enabled collaborative exploration of the intersection of mobile learning and curriculum redesign to enable new pedagogies that focus upon student-generated contexts and collaboration via mobile social media. The design process was informed by a mobile social media framework for creative pedagogies and the project outcomes have been critically evaluated and disseminated by the scholarship of teaching and learning (SOTEL) providing a potentially transferable solution to enabling new pedagogies within a variety of educational contexts.

\section{References}

Bannan, B., Cook, J., \& Pachler, N. (2015). Reconceptualizing design research in the age of mobile learning. Interactive Learning Environments, 24(5), 1-16. doi:10.1080/10494820.2015.1018911

Boyer, E. (1990). Scholarship reconsidered: priorities of the professoriate. Princeton, NJ: Carnegie Foundation for the Advancement of Teaching.

Cochrane, T. (2014). Critical success factors for transforming pedagogy with mobile Web 2.0. British Journal of Educational Technology, 45(1), 65-82. doi:10.1111/j.1467-8535.2012.01384.x

Cochrane, T., \& Antonczak, L. (2015). Connecting the theory and practice of mobile learning: a framework for creative pedagogies using mobile social media. Media Education, 6(2), 248-269.

Cochrane, T., Antonczak, L., Guinibert, M., Withell, A., Mulrennan, D., Mountfort, P., \& Narayan, V. (2013, 1-4 December). Collaboration unplugged: Herding a flock of MOAs. Paper presented at the Electric Dreams: 30th ascilite Conference, Macquarie University, Sydney, Australia.

Cochrane, T., Guinibert, M., Simeti, C., Brannigan, R., \& Kala, A. (2014). Mobile Social Media as a Catalyst for Collaborative Curriculum Redesign. In J. Keengwe \& M. Maxfield (Eds.), Advancing Higher Education with Mobile Learning Technologies: Cases, Trends, and Inquiry-Based Methods (pp. 1-21). Hershey, PA: IGI Global.

Cochrane, T., Mulrennan, D., Sissons, H., Pamatatau, R., \& Barnes, L. (2013, 4-6 July). Mobilizing Journalism Education. Paper presented at the International Conference on Information Communication Technologies in Education (ICICTE 2013), Crete, Greece. 
Pacific Journal of Technology Enhanced Learning, 2020, 2(2).

Cochrane, T., \& Narayan, V. (2016). Evaluating a Professional Development cMOOC: MOSOMELT. In S. Barker, S. Dawson, A. Pardo, \& C. Colvin (Eds.), Show Me The Learning. Proceedings ASCILITE 2016 Adelaide (pp. 139-150). University of South Australia, Adelaide, Australia: Ascilite.

Cochrane, T., \& Narayan, V. (2017). Design Considerations for Mobile Learning. In C. Reigeluth, B. J. Beatty, \& R. Myers (Eds.), Instructional-Design Theories and Models (Vol. 4, pp. 385-414). New York: Routledge.

Cochrane, T., Narayan, V., Brannigan, R., Frenchman, K., Nicholson, E., Rutherford, S., . . Neill, C. (2014). \#NPF14LMD AUT University Case Studies. Paper presented at the Rhetoric and Reality, proceedings of the 31st Ascilite Conference, Otago Polytechnic, Dunedin. Poster retrieved from http://ascilite2014.otago.ac.nz/posters/\#291

Cochrane, T., Narayan, V., Burcio-Martin, V., Lees, A., \& Diesfeld, K. (2015, 29 November - 2 December). Designing an authentic professional development cMOOC. Paper presented at the Globally connected, digitally enabled, Proceedings the 32nd Ascilite Conference, Curtin University, Perth.

Cochrane, T., Narayan, V., \& Oldfield, J. (2015). Emerging technologies in New Zealand: A pedagogical framework for mobile social media. In V. Bozalek, D. Ngambi, A. Amory, J. Hardman, D. Wood, \& J. Herrington (Eds.), Activity theory, authentic learning, and emerging technologies: Southern perspectives (pp. 126-143). New York: Routledge.

Cochrane, T., Sissons, H., Mulrennan, D., \& Pamatatau, R. (2013). Journalism 2.0: Exploring the impact of Mobile and Social Media on Journalism Education. International Journal of Mobile and Blended Learning, 5(2), 22-38. doi:10.4018/jmbl.2013040102

Cochrane, T., \& Withell, A. (2013). Augmenting design education with mobile social media: A transferable framework. Journal of the NUS teaching academy, 3(4), 150-168.

Cook, J. (2009). Phases of mobile learning. Joint European summer school on technology enhanced learning, (May 30 - June 6). Retrieved from http://www.slideshare.net/johnnigelcook/cook-phases-of-mobile-learning

Cook, J., \& Santos, P. (2016). Three Phases of Mobile Learning State of the Art and Case of Mobile Help Seeking Tool for the Health Care Sector. In D. Churchill, J. Lu, T. K. F. Chiu, \& B. Fox (Eds.), Mobile Learning Design (pp. 315-333): Springer Singapore.

Cormier, D. (2008). Rhizomatic education: Community as curriculum. Innovate, 4(5), np. available http://davecormier.com/edblog/2008/2006/2003/rhizomatic-education-community-as-curriculum/.

Danvers, J. (2003). Towards a radical pedagogy: Provisional notes on learning and teaching in art \& design. International Journal of Art \& Design Education, 22(1), 47-57. doi:10.1111/1468-5949.00338

Dimitriadis, Y., \& Goodyear, P. (2013). Forward-oriented design for learning: illustrating the approach. 2013, 21. doi:10.3402/rlt.v21i0.20290

Educause Learning Initiative. (2012). 7 Things You Should Know About Educational Design Research. 7 Things You Should Know About... 2012(6 August). Retrieved from http://www.educause.edu/library/resources/7things-you-should-know-about-educational-design-research

Educause Learning Initiative. (2014). 7 Things You Should Know About Design Thinking. 7 Things You Should Know About... 2014(3 June). Retrieved from http://www.educause.edu/library/resources/7-things-youshould-know-about-design-thinking

Frielick, S., Cochrane, T., Aguayo, C., Narayan, V., O'Carrol, D., Smith, N., . . Wyse, P. (2014, 12 April 2015). Learners and mobile devices (\#NPF14LMD): A framework for enhanced learning and institutional change. Retrieved from https://akoaotearoa.ac.nz/learner-mobile-devices

Frohberg, D., Goth, C., \& Schwabe, G. (2009). Mobile learning projects - a critical analysis of the state of the art. Journal of Computer Assisted Learning, 25(4), 307-331. doi:10.1111/j.1365-2729.2009.00315.x

Goodyear, P. (2011). Emerging Methodological Challengesmethodological challenges for educational research for Educational Researchresearch educational. In L. Markauskaite, P. Freebody, \& J. Irwin (Eds.), Methodological Choice and Design: Scholarship, Policy and Practice in Social and Educational Research (pp. 253-266). Dordrecht: Springer Netherlands.

Haigh, N. (2010). National Office, Wellington, New Zealand: Ako Aotearoa.

Hase, S., \& Kenyon, C. (2001). From Andragogy to Heutagogy. ultiBASE Articles, (December), 1-10. Retrieved from http://www.psy.gla.ac.uk/ steve/pr/Heutagogy.html

Hase, S., \& Kenyon, C. (2007). Heutagogy: a child of complexity theory. Complicity: an International Journal of Complexity and Education, 4(1), 111-118. doi:https://doi.org/10.29173/cmplct8766

Kenobi, B., \& Cochrane, T. (2015). Innovative Pedagogy in Game Design. In S. Frielick (Ed.), LTDF 2014 ebook (pp. 79-81). Auckland University of Technology: Centre for Learning And Teaching. 
Leinonen, T., \& Durall, E. (2014). Design Thinking and Collaborative Learning. Comunicar, 42(1), 107-115. doi:http://dx.doi.org/10.3916/C42-2014-10

Luckin, R., Clark, W., Garnett, F., Whitworth, A., Akass, J., Cook, J., . . Robertson, J. (2010). Learner-Generated Contexts: A Framework to Support the Effective Use of Technology for Learning. In M. Lee \& C. McLoughlin (Eds.), Web 2.0-Based E-Learning: Applying Social Informatics for Tertiary Teaching (pp. 70-84). Hershey, PA: IGI Global.

McKenney, S., \& Reeves, T. (2012). Conducting educational design research. London: Routledge.

McKenny, S., \& Visscher-Voerman, I. (2013). Formal education of curriculum and instructional designers. Educational Designer, 2(6).

Mitchell, G., Matthews, G., Pospisil, R., \& White, B. (2009, 6th-9th July). Space Matters - Particularly when you don't have a lot. Paper presented at the HERDSA, Charles Darwin University, Darwin, Australia.

Puentedura, R. (2006). Transformation, Technology, and Education. Retrieved from http://hippasus.com/resources/tte/puentedura tte.pdf

Punie, Y. (2013). Up-Scaling Creative Classrooms in Europe (SCALE CCR). Retrieved from http://is.jrc.ec.europa.eu/pages/EAP/SCALECCR.html

Reeves, T. (2005). No significant differences revisited: A historical perspective on the research informing contemporary online learning. In G. Kearsley (Ed.), Online learning: Personal reflections on the transformation of education (pp. 299-308). Englewood Cliffs, NJ: Educational Technology Publications.

Rushby, N. (2012). Editorial: An agenda for mobile learning. British Journal of Educational Technology, 43(3), 355-356. doi:10.1111/j.1467-8535.2012.01313.x

Salmon, G., \& Angood, R. (2013). Sleeping with the enemy. British Journal of Educational Technology, 44(6), 916925. doi:10.1111/bjet.12097

Scott-Webber, L., \& Corcorran, S. (2013, July 25). Design Thinking: Theory and practice. EDUCAUSE Live! Webinars. Retrieved from http://www.educause.edu/library/resources/design-thinking-theory-and-practice

Sharples, M. (2009, October 26-30). Learning at large. Paper presented at the MLearn 2009: The 8th World Conference on Mobile and Contextual Learning, University of Central Florida, Institute for Simulation and Training, Orlando, Florida.

Siemens, G. (2004). Connectivism: A Learning Theory for the Digital Age. eLearnspace, (12 December). Retrieved from http://www.elearnspace.org/Articles/connectivism.htm

Sternberg, R. J., Kaufman, J. C., \& Pretz, J. E. (2002). The creativity conundrum: A propulsion model of kinds of creative contributions. Philadelphia: Psychology Press.

Vygotsky, L. (1978). Mind in Society. Cambridge, MA: Harvard University Press.

Weaver, D., Robbie, D., Kokonis, S., \& Miceli, L. (2012). Collaborative scholarship as a means of improving both university teaching practice and research capability. International Journal for Academic Development, 18(3), 237-250. doi:10.1080/1360144x.2012.718993

Wickens, R. (2006). SoTEL: Toward a Scholarship of Technology Enhanced Learning. Canadian Journal of University Continuing Education 32(2), 21-41.

Wingkvist, A., \& Ericsson, M. (2011). A survey of research method and purposes in mobile learning. International Journal of Mobile and Blended Learning, 3(1), 1-17. doi:10.4018/jmbl.2011010101 